2. Луценко М. С. Механизм обеспечения гибкости производственных систем в условиях развития инновационной деятельности // Дисс. канд. эконом. наук / Воронежский государственного технического университета Воронеж, 2008.

3. Пешкова И. В., Луценко М. С. Оценка системы стратегического управления предприятия в условиях инновационных изменений // Вестник Воронежского государственного технического университета. 2006. - С. 100.

4. Шендрикова О. О. Организация производства как фактор повышения эффективности производственной системы В сб.: Качество продукции: контроль, управление, повышение, планирование/ Сб. науч. тр. Междунар. молодеж. науч.-практ. конф.: В 2 т. Отв. ред.: Павлов Е. В. 2015. - С. $370-375$.

\title{
Фадейкина В.С., Боровик А.В. \\ Исследование изменения мотивационной структуры личности персонала промышленного предприятия в зависимости от возраста
}

Сибирский государственный университет путей сообщения (Россия, Новосибирск)

doi: $10.18411 / 1 j-06-2021-89$

\section{Аннотация}

В статье представлены результаты исследования мотивационной структуры личности персонала промышленного предприятия при помощи методики В.Э. Мильмана. В результате исследования авторам удалось проследить изменение мотивационной структуры личности, в зависимости от возраста персонала. Также авторы предложили возможные варианты мотивации сотрудников разных возрастных групп. Результаты исследования могут быть использованы в разработке мотивационных программ промышленных предприятий для персонала, деятельность которого жестко регламентирована требованиями и инструкциями.

Ключевые слова: мотивационная структура личности, мотивация персонала, мотиваторы, управление персоналом.

\section{Abstract}

The article presents the results of the study of the motivational structure of the personality of the personnel of an industrial enterprise using the methodology of $\mathrm{V}$. E. Milman. As a result of the study, the authors were able to trace the change in the motivational structure of the individual, depending on the age of the staff. The authors also suggested possible options for motivating employees of different age groups. The results of the study can be used in the development of motivational programs of industrial enterprises for personnel whose activities are strictly regulated by the requirements and instructions.

Keywords: motivational structure of the individual, personnel motivation, motivators, personnel management.

Мотивационная структура личности представляет собой совокупность смыслообразующих мотивов, которые определяют общую направленность потребностей и интересов личности.

Большое внимание в управлении персоналом должно уделяться методам мотивации персонала. [1] При разработке программ мотивации важно знать мотивационную структуру личности сотрудников и предлагать мотиваторы, интересные именно для персонала данной организации. Внутреннее побуждение, формируется под воздействием личных ощущений, основанных на особенностях процесса социализации личности, опыте, знаниях, ее социальной направленности. [2]

Понятие мотивации в психологии человека - это побуждения, вызывающие активность организма и определяющие ее направления; в управлении персоналом мотивация характеризуется как процесс, побуждающий человека к достижению личных целей или целей организации. [3] Важную роль в работе играет мотивация и 
мотивационная структура личности человека, ведь именно она определяет потребности работника, а следовательно и подход к разработке программ мотивации. Уровень рабочих результатов сотрудников организации не всегда является отражением их знаний, способностей, опыта и квалификации. Значительное влияние на него оказывают такие факторы, как уровень работоспособности, особенности личности и деловые качества работника, уровень мотивации, которая определяет, то в какой степени человек реализует свой профессиональный потенциал в работе. В этой связи необходимо правильно выбрать способы воздействий и добиться оптимального функционирования [4].

Важно отметить, что мотивационные структуры личностей сотрудников одного коллектива могут быть очень разнообразными, на ее формирование оказывают влияние такие факторы как: стаж работы, пол, возраст, образование, семейное положение, социальный статус, специфика труда, тип организационной культуры и многие другие факторы. Мы предполагаем, что мотивационная структура личности может меняться в зависимости от возраста сотрудника.

Для проверки данного предположения было проведено исследование в Эксплуатационном локомотивном депо г. Ачинска - структурном подразделении дирекции тяги - структурного подразделения Красноярской железной дороги (ТЧЭ- 5 г. Ачинск). Объектом исследования выступили сотрудники локомотивных бригад, поскольку именно они являются основной категорией персонала организации. В локомотивных бригадах работают люди разных возрастных групп и каждого из них нужно мотивировать по-своему. В ходе исследования необходимо рассмотреть, изменяется ли мотивационная структура работников локомотивных бригад в зависимости от возраста.

Исследование проводилось при помощи теста «Диагностика мотивационной структуры личности» В.Э. Мильмана. [5] Методика диагностики мотивационной структуры личности В.Э. Мильмана позволяет диагностировать мотивационный и эмоциональный профили личности . На основе соотношения показателей всех шкал, выводимых в результате тестирования можно выделить определенные типы мотивационного профиля. Шкалы мотивационного профиля: поддержание жизнеобеспечения (П),- комфорт (К), социальный статус $(\mathrm{C})$, общение $(\mathrm{O})$, общая активность (Д), творческая активность (ДР), общественная полезность (ОД).

Для проведения исследования респонденты, принявшие участие в исследовании, были разделены на несколько групп (до 30 лет, от 31 до 40 лет, 40 до 50 лет, старше 51 года). Соотношение генеральной и выборочной совокупности исследования представлено на рисунке 1.

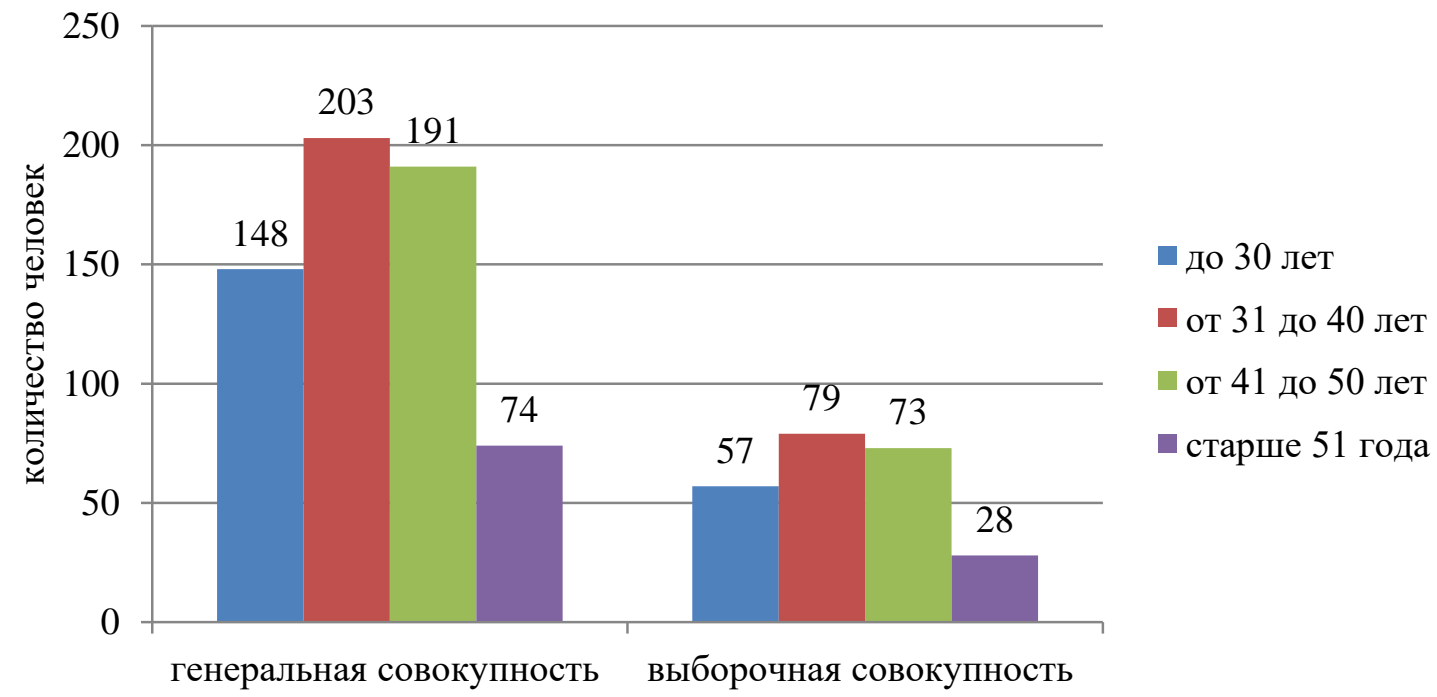

Рисунок 1 - Соотношение генеральной и выборочной совокупности исследования 
Расчеты выборочной совокупности выполнялись методом пропорции. На рисунке 1 видно, что пропорционально выборочная совокупность соответствует генеральной. Результаты исследования представлены на рисунке 2.

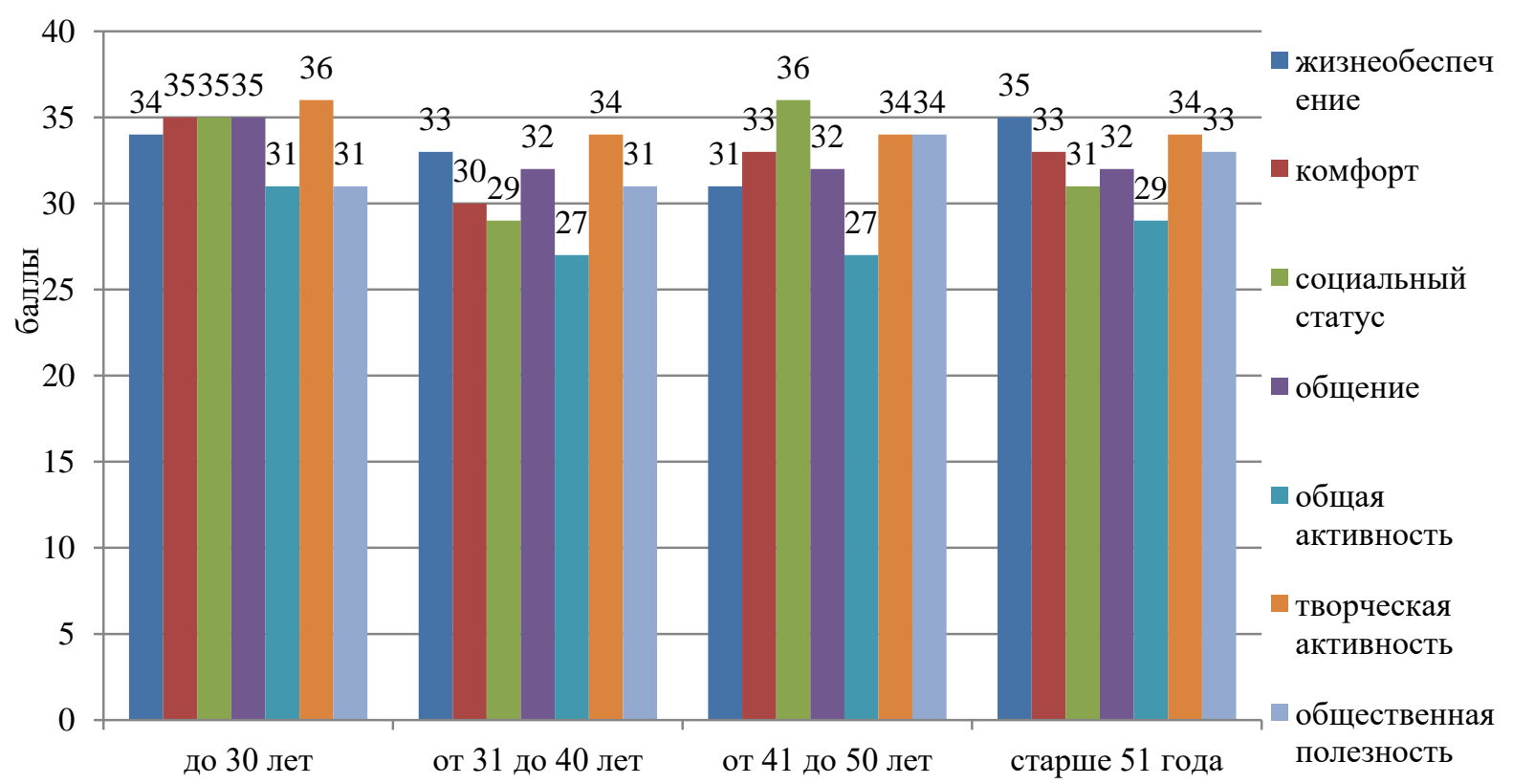

Рисунок 2 - результаты исследования мотиваџионной структуры личности

Исходя из полученных данных можно сделать вывод о том, что для работников до 30 лет наиболее важным мотивирующим фактором является возможность творческой активности. Для самых молодых сотрудников организации важно предоставлять возможность использовать свою энергию, получать творческие результаты от профессиональной деятельности. Для данной группы сотрудников важно создавать условия для реализации творческого потенциала. Поскольку работа в локомотивных бригадах предполагает четкое следование инструкциям, приказам и правилам важно создавать возможность реализации потребности в творческой активности за пределами производственного процесса. Организовывать участие молодежи в рационализаторстве, в конкурсах и мероприятиях организуемых ОАО РЖД в рамках молодежной политики.

У персонала в возрастной группе от 31 до 40 лет в целом интенсивность мотивационного профиля несколько ниже чем в группе до 30 лет. У данной возрастной группы также преобладает мотивационный фактор «творческая активность», вторым по важности мотивационным фактором является «жизнеобеспечение», отражающее стремление обеспечить свою семью материальным благосостоянием, а также восстановлением здоровья. Для данной категории сотрудников также важно создавать условия для творческой активности, а также уделять внимание вопросам восстановления здоровья, отдыха, медицинского обслуживания и реабилитации. Важным мотивирующим фактором данной категории персонала является достойная заработная плата, обеспечивающая достойный уровень жизни всех членов семьи.

Для сотрудников в возрастной группе от 41 до 50 лет наиболее важным мотивационным фактором является «статусно-престижная мотивация». Для данных сотрудников важен комфорт в социальной сфере, внимание окружающих, престиж, репутация, уважение, положение в обществе. В качестве мотивации данных сотрудников можно использовать такие инструменты, как публичная похвала, признание заслуг, награждение почетными знаками или статусами. Именно данную 
категорию сотрудников целесообразно назначать наставниками молодых сотрудников, использовать их опыт и знания для передачи молодежи компании.

Для категории персонала старше 51 года вновь становится важным мотивирующий фактор - «жизнеобеспечение». Данную тенденцию можно объяснить появлением заболеваний, в том числе обусловленных профессиональной деятельностью, подготовкой к выходу на пенсию. Для данной категории сотрудников важно разрабатывать мотивационные программы связанные с возможностью восстановления и поддержания здоровья, разработки программ health management.

Анализируя общие результаты исследования для всех возрастных групп можно отметить, что у персонала данной должностной категории в данной организации в целом низкая общая активность. Сотрудников локомотивных бригад не будет мотивировать к труду дополнительная общественная нагрузка, которая не способствует их личной самореализации. В тоже время у всех возрастных групп сотрудников локомотивных бригад наблюдается высокая потребность в творческой активности. Возможно, что потребность в творческой активности является фрустрированной потребностью, вызванной спецификой работы в условиях жесткой регламентации, инструктирования, соблюдения всех требований и правил, обеспечивающих жизнь и здоровье пассажиров.

В результате проведенного исследования можно сделать вывод, что мотивационная сфера личности меняется с возрастом сотрудников. При разработке программ мотиваций персонала необходимо использовать разные мотиваторы для разных возрастных категорий персонала.

$$
* * *
$$

1. Галанова Е.В. Анализ ценностно-мотивационной структуры личности сотрудников промышленного предприятия: профессионально-квалификационный, гендерный и возрастной аспекты // Вестник современных исследований. - 2018. - №1.1 (16) . - С 195-197.

2. Мордвинова Е.Л. Управление мотивацией трудового поведения россиян // Системное обеспечение условий достойного труда. Материалы I Всероссийской научно-практической конференции.Новосибирск: Сибирский государственный университет путей сообщения.- 2017. - С. 90-97.

3. Козина Е.С. формирование и развитие мотивационного потенциала современной организации // Вестник Сибирского государственного университета путей сообщения. - 2013. - № 29. - С. 110118.

4. Фадейкина В.С. Социологический анализ регионального потенциала управления детством в г. Новосибирске // Вестник Томского государственного университета. - 2010. - № 337. - С. 59-62.

5. Мильман В.Э. Метод изучения мотивационной сферы личности / Практикум по психодиагностике. Психодиагностика мотивации и саморегуляции. - М., 1990. 